\title{
Optimization and validation of the salting-out assisted liquid-liquid extraction method and analysis by gas chromatography to determine pesticides in water
}

\author{
Alessandra Aparecida Zinato Rodrigues ${ }^{1}$, Antônio Augusto Neves ${ }^{1(\mathbb{D}}$, Maria Eliana Lopes Ribeiro de Queiroz ${ }^{1(\mathbb{B})}$, \\ André Fernando de Oliveira ${ }^{10}$, Lucas Henrique Figueiredo Prates ${ }^{2(1)}$, Elisa Helena da Costa Morais \\ ${ }^{1}$ Federal University of Viçosa (UFV), Center of Exact and Technological Sciences, Peter Henry Rolfs Av, Viçosa, Minas Gerais, Brazil \\ 2 Federal University of Viçosa (UFV), Center of Agricultural Sciences, Peter Henry Rolfs Av, Viçosa, Minas Gerais, Brazil
}

\section{ARTICLE INFO}

Article history:

Received: December 28, 2017

Accepted: May 31, 2018

Published: June 28, 2018
Keywords
1. contamination of water
2. pesticide
3. gas chromatography

ABSTRACT: The salting-out assisted liquid-liquid extraction (SALLE) was developed for the analysis of four pesticides (cypermethrin, chlorpyrifos, deltamethrin, and thiamethoxam) in water samples. For its optimization, a $2^{3}$ factorial design was used to evaluate the simultaneous behavior of three factors: sample and extraction solvent ratio, saline concentration, and stirring mode. 1.0 $\mathrm{mL}$ saline solution $(\mathrm{NaCl})$ was added to the single-phase mixture of water and extraction solvent to separate the phases. The mixture was stirred, allowed to stand and the top organic phase containing the pesticides of interest was analyzed by gas chromatography coupled with electron capture detector (GC/ECD). The optimized method was

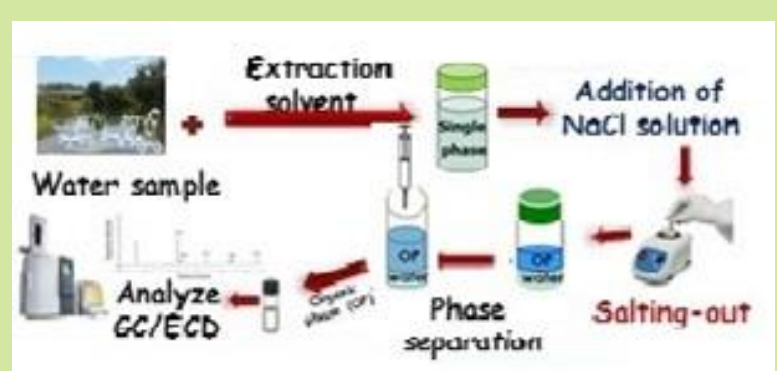
validated for some merit figures. The limit of detection of the method ranged from 0.15 to $5.5 \mu \mathrm{g} \mathrm{L}^{-1}$ and the limit of quantification from 5.5 to $18.2 \mu \mathrm{g} \mathrm{L}^{-1}$. The method showed satisfactory results for the linearity $\left(\mathrm{R}^{2} \geq 0.990\right)$, precision $(\mathrm{CV}<9 \%)$ and accuracy $(72 \% \leq$ recovery $\leq 90 \%)$ for all the assessed analytes. The method showed to be simple, efficient and inexpensive for the extraction of pesticide residues. The validated method was applied to ten samples of water collected in the Zona da Mata region of the state of Minas Gerais, Brazil.

\section{Introduction}

Indiscriminate use and improper application of pesticides can generate residues of potentially toxic substances in the environmental compartments: soil, water, and air, as well as food, thus causing serious problems to the environment and to human health ${ }^{1,2,3}$.

The use of pesticides is the second largest cause of contamination of rivers in Brazil, second only to domestic sewage ${ }^{4}$. Contamination of water by pesticides can occur through the transmission of aerial sprays, through the erosion of contaminated soils, surface runoff, leaching, and the disposal and washing of tanks and product packaging ${ }^{5,6}$.

Therefore, special attention should be given to drinking water, as daily consumption of water contaminated with pesticide residues can cause toxic effects such as cancer and damage to the central nervous system, depending on the type of compound and the amount ingested. In Brazil, the norms on the drinking water potability and quality for human consumption are established by the Ministry of Health in which allowed values are presented for microbiological, 
organoleptic, physical and chemical characteristics ${ }^{7}$.

Pesticide residues analyses in water samples are difficult to be executed since these compounds have very different physicochemical properties and occur at extremely low concentrations in the presence of high concentrations of interfering compounds ${ }^{8}$.

The first step for analysis and monitoring of pesticide residues in water involves the development of an extraction technique. The goal of this step is to remove selectively the pesticide residues from the samples and promote their preconcentration'. Thus, techniques for the determination of pesticide residues in different matrices have significantly evolved in simplification, improvement of extraction and purification of samples, with the main objectives of minimizing sample and solvent consumption ${ }^{10}$.

Several studies in the literature reported the determination of pesticide residues in water using the techniques of sample preparation solidphase extraction - $\mathrm{SPE}^{11} ;$ solid-phase microextraction - $\mathrm{SPME}^{1,12}$; liquid-liquid extraction with low temperature partitioning LLE-LTP $^{13,}{ }^{14}$; liquid phase microextraction LPME $^{15,16}$; dispersive liquid-liquid microextraction - DLLME $^{17,}{ }^{18}$; single drop microextraction - $\mathrm{SDME}^{19}$. Despite the high number of existing techniques, the salting-out assisted liquid-liquid extraction (SALLE) technique emerged as a new alternative for the extraction of pesticide residues in water based on its advantages of simplicity of operation, rapidity (brief time for phase separation), low volume of both sample and solvent, low cost, safety and good sensitivity. In addition, sample preparation is the largest source of errors in trace analysis, thus a rapid and simple extraction step improves the method as a whole.

The extraction technique is based on the partitioning of the compounds between the initially miscible aqueous and organic phases, which are separated by the addition of salts. This behavior can be explained in terms of solvation of the ions by the water molecules, facilitating the migration of pesticides to the organic phase. This salt addition effect is known as salting-out and may cause a decrease in the solubility of certain analytes in the aqueous phase, in favor of the extraction ${ }^{20,21}$.

After the extraction step, the determination of the pesticides residues on several matrices is traditionally carried out by chromatographic techniques due to the ease of separation, identification, and quantification of the substances present in the sample. Furthermore, gas chromatography is specially used for pesticide residues determination due to the low limits of detection that can be achieved ${ }^{22}$.

In Brazil some pesticides widely used for pest control belong to chemical groups of organophosphates, pyrethroids and neonicotinoids. In this context, the aim of this study was to optimize and validate the salting-out assisted liquid-liquid extraction (SALLE) technique followed by gas chromatography analysis (SALLE - GC/ECD) for the determination of four pesticides belonging to these chemical groups (Figure 1) in water. The proposed method was applied to 10 samples of water collected in the Zona da Mata of Minas Gerais, Brazil.
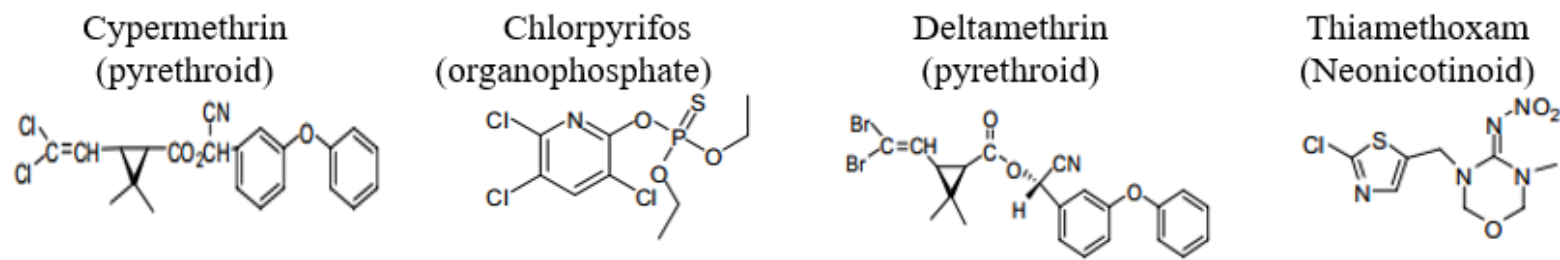

Figure 1. Chemical groups and structures of the pesticides cypermethrin, chlorpyrifos, deltamethrin, and thiamethoxam.

\section{Experimental}

\subsection{Chemicals and reagents}

Analytical standards of chlorpyrifos (99.0\% $\mathrm{w} / \mathrm{w})$, cypermethrin $(92.4 \% \mathrm{~m} / \mathrm{m})$, and deltamethrin $(99.0 \% \mathrm{w} / \mathrm{w})$ were purchased from Chem Service (West Chester, PA, USA), thiamethoxam $(99.7 \% \mathrm{w} / \mathrm{w})$ was purchased 
from Sigma Aldrich (Germany) and the bifenthrin $(92.2 \% \mathrm{w} / \mathrm{w})$, used as internal standard, was purchased from FMC do Brasil. Stock solutions of $500.0 \mathrm{mg} \mathrm{L}^{-1}$ of all analytical standards in acetonitrile (Mallinckrodt/ HPLC) were prepared and stored in freezer. Diluted solutions were prepared from the stock solutions to obtain the working solutions at different concentrations with the four pesticides. Sodium chloride (Reagen - P.A. $99.5 \%$ w/w) solutions were used to break the equilibrium (salting-out effect).

\subsection{Chromatographic conditions}

Identification and quantification of the pesticides extracted from the samples were done with a gas chromatograph equipped with an electron capture detector system (GC/ECD) (Shimadzu GC-2014, Kyoto, Japan), and autoinjector AOC - 20i. The separations were performed on an HP-5 capillary column, $30 \mathrm{~m}$ long, $0.25 \mathrm{~mm}$ inner diameter, and $0.10 \mu \mathrm{m}$ film thickness (Agilent Technologies, Palo Alto, CA, USA), with the stationary phase consisting of phenyl $5 \%$ and dimethylsiloxane $95 \%$. Nitrogen (99.999 \%, Air Products, Brazil) was used as carrier gas at $1.2 \mathrm{~mL} \mathrm{~min}^{-1}$. Injector and detector temperatures were set at 280 and $300{ }^{\circ} \mathrm{C}$, respectively. The initial column oven temperature was $150{ }^{\circ} \mathrm{C}$, with a heating rate of $20^{\circ} \mathrm{C} \mathrm{min}^{-1}$ up to $250{ }^{\circ} \mathrm{C}$, and $10^{\circ} \mathrm{C} \min ^{-1}$ up to $290{ }^{\circ} \mathrm{C}$ maintained for $5 \mathrm{~min}$. The injected volume was 1 $\mu \mathrm{L}$ at a split ratio of $1: 5$. The total running time was 14 min.

\subsection{Fortified samples}

Samples of distilled water (pesticides free) fortified with the working solutions containing the four pesticides were used in different concentrations for the optimization and validation of the method. Fortified water samples were allowed to stand for $3 \mathrm{~h}$, at room temperature for solvent evaporation, prior to use. The technique was submitted to a multivariate optimization with the evaluation of three parameters (i) volume ratio of sample: extraction solution, (ii) saline solution concentration, and (iii) stirring mode.

\subsection{Experimental design}

The salting-out assisted liquid-liquid extraction (SALLE) method was optimized using a factorial design $2^{3}$ to evaluate the influence of the variables on the extraction yield of the four pesticides. The following factors were evaluated: ratio between the water volume and the volume of the solvent extractor, acetonitrile and ethyl acetate, $(4.5 / 6.5$ or $3.0 / 6.0 \mathrm{~mL})$; sodium chloride solution concentration $\left(1.0\right.$ or $2.0 \mathrm{~mol} \mathrm{~L}^{-1}$ of $\mathrm{NaCl}$ ); stirring mode (40 $\mathrm{s}$ at the vortex or $10 \mathrm{~min}$ at the orbital shaker with $175 \mathrm{rpm}$ and $\left.25^{\circ} \mathrm{C}\right)$. The data corresponding to the $(-)$ and $(+)$ levels of factorial design are shown in Table 1 . The tests in duplicate allowed to calculate the average recovery percentages of pesticides (Table 1). The levels of the three factors used in factorial planning were established in previous experiments.

After stirring, the solutions were allowed to stand and the upper organic phase containing the analytes of interest was withdrawn with a volumetric pipet. The volumes of the extracts were adjusted with acetonitrile in a $5.0 \mathrm{~mL}$ volumetric flask containing $100 \mu \mathrm{L}$ of bifenthrin solution at $5.0 \mathrm{mg} \mathrm{L}^{-1}$ (internal standard). The extracts were analyzed by gas chromatography coupled to an electron capture detector (CG). The best conditions of the factorial design were evaluated according to the chromatographic responses (areas) obtained in each experiment. The obtained data were analyzed using the Excel ${ }^{\circledR}$ and OriginPro®. 
Table 1. Factorial design $2^{3}$ and evaluated factors: (F1) ratio between the water and extraction solvent volume, (F2) sodium chloride solution concentration, (F3) stirring mode.

Coded factors

\begin{tabular}{|c|c|c|c|c|c|c|}
\hline \multirow[b]{2}{*}{ Experiment } & \multicolumn{3}{|c|}{ 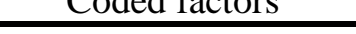 } & \\
\hline & $\mathrm{F}(1)$ & $\mathrm{F}(2)$ & $\mathrm{F}(3)$ & $\begin{array}{c}\text { (1) } \mathrm{H}_{2} \mathrm{O} \text { :solvent } \\
\text { ratio } \\
(\mathrm{v} / \mathrm{v}) \\
\end{array}$ & $\begin{array}{l}\text { (2) Saline } \\
\text { solution conc. } \\
\left(\mathrm{mol} \mathrm{L}^{-1}\right)\end{array}$ & (3) Stirring mode \\
\hline 1 and 2 & - & - & - & $4.5 / 5.0 / 1.5(\mathrm{~A})$ & 1.00 & Vortex $(40 \mathrm{~s})$ \\
\hline 3 and 4 & + & - & - & 3.0/5.0/1.0 (B) & 1.00 & Vortex (40 s) \\
\hline 5 and 6 & - & + & - & 4.5/5.0/1.5 (A) & 2.00 & Vortex $(40 \mathrm{~s})$ \\
\hline 7 and 8 & + & + & - & 3.0/5.0/1.0 (B) & 2.00 & Vortex (40 s) \\
\hline 9 and 10 & - & - & + & 4.5/5.0/1.5 (A) & 1.00 & Orbital shaker (10 min) \\
\hline 11 and 12 & + & - & + & $3.0 / 5.0 / 1.0(\mathrm{~B})$ & 1.00 & Orbital shaker (10 min) \\
\hline 13 and 14 & - & + & + & 4.5/5.0/1.5 (A) & 2.00 & Orbital shaker (10 min) \\
\hline 15 and 16 & + & + & + & $3.0 / 5.0 / 1.0(\mathrm{~B})$ & 2.00 & Orbital shaker (10 min) \\
\hline
\end{tabular}

\subsection{Method validation}

The validation of the optimized SALLE method for pesticide residue determination in water was assessed with the following merit parameters: selectivity, linearity, limits of detection (LOD) and quantification (LOQ), precision (repeatability and intermediate precision), and accuracy (recovery and methods comparison). The validation procedures followed the recommendations of the International Conference on Harmonization $(\mathrm{ICH})^{23}$, the Brazilian Health Regulatory Agency (ANVISA) ${ }^{24}$, and the National Institute of Metrology, Quality and Technology (INMETRO) ${ }^{25}$.

\subsection{SALLE application in water samples}

The optimized and validated SALLE method for determination of pesticides in water was applied in eight samples of water collected in rivers at the Zona da Mata of Minas Gerais State. The sampling was done at the municipalities of Manhuaçu, Matipó, Raul Soares and Rio Casca, where there is a major planting of coffee and citrus fruits. Also, two samples of tap water were taken from the water distribution network of the water treatment station of the Universidade Federal de Viçosa (municipality of Viçosa, Minas Gerais, Brazil).

\section{Results and discussion}

\subsection{Chromatographic analysis}

The chromatogram of the standard solution with the four pesticides at $100 \mu \mathrm{gL}^{-1}$ in acetonitrile is presented in Figure 2. The third peak, with retention time $\left(\mathrm{R}_{\mathrm{t}}\right)$ of $8.3 \mathrm{~min}$, corresponds to the internal standard, bifenthrin. The multiple peaks observed at the chromatogram are related to the conversion to isomers of the pyrethroids (cypermethrin and deltamethrin) in the chromatograph injector. The quantification of these two pyrethroids was done considering the total area of both peaks of the isomers, both at the standard analysis and at samples analysis.

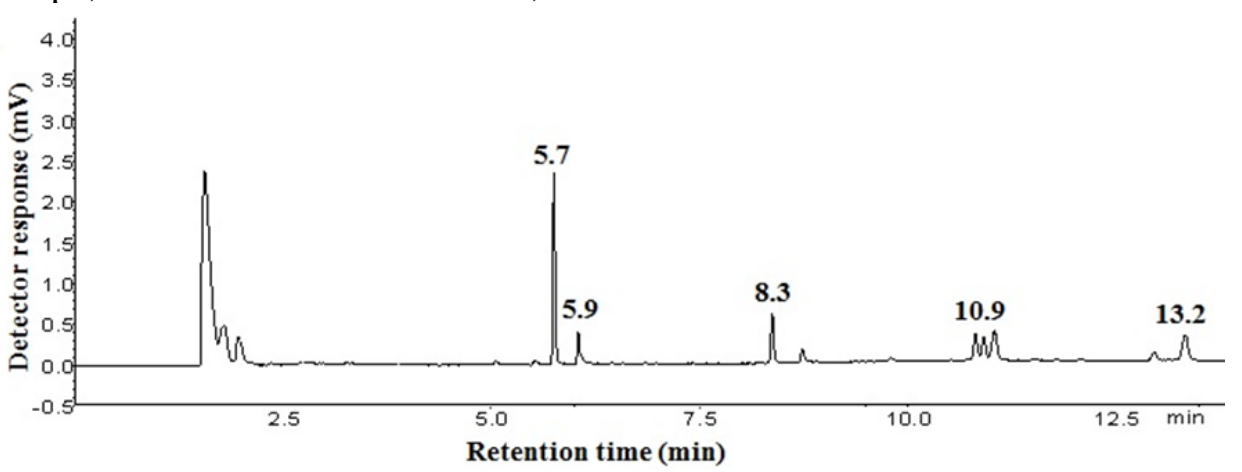

Figure 2. Chromatogram of the standard solution with the four pesticides and internal standard at $100.0 \mu \mathrm{g} \mathrm{L}^{-1}$ in acetonitrile, where: $R_{t}=5.7$ min: chlorpyrifos, $R_{t}=5.9$ min: thiamethoxam, $R_{t}=8.3$ min: bifenthrin (IS) $R_{t}=10.9$ min: cypermethrin, and $R_{t}=13.2$ min: deltamethrin. 


\subsection{Optimization of the salting-out assisted liquid- liquid extraction method}

The optimization of the extraction technique evaluated three factors simultaneously: the ratio between sample and extraction solvent volumes, the $\mathrm{NaCl}$ concentration, and the stirring mode of the mixture. In this evaluation, a factorial design
$2^{3}$ was conducted and the effects evaluated by recovery percentages. The tests, performed in duplicate, generated 16 responses that allowed to estimate the experimental errors associated to the determination of each mean response. Table 2 highlights the trials that obtained the best recovery percentages for the four pesticides analyzed in water samples.

Table 2. Percentages of mean recovery and estimation of the experimental error obtained in the experiments of the factorial design for water samples containing the pesticides chlorpyrifos, thiamethoxam, cypermethrin, and deltamethrin extracted by salting-out assisted liquid-liquid extraction method.

Coded factors Recovery $(\%) \pm$ estimation of the experimental error

\begin{tabular}{cccccccl}
\hline Experiment & $\mathrm{F}(1)$ & $\mathrm{F}(2)$ & $\mathrm{F}(3)$ & Chlorpyrifos & Thiamethoxam & Cypermethrin & Deltamethrin \\
\hline 1 and 2 & - & - & - & $89 \pm 8$ & $50 \pm 12$ & $69 \pm 10$ & $72 \pm 11$ \\
3 and 4 & + & - & - & $67 \pm 6$ & $49 \pm 11$ & $70 \pm 8$ & $72.1 \pm 0.6$ \\
5 and 6 & - & + & - & $86 \pm 4$ & $67 \pm 16$ & $76 \pm 9$ & $85 \pm 19$ \\
$\mathbf{7}$ and 8 & + & + & - & $\mathbf{8 8 . 9} \pm \mathbf{0 . 2}$ & $\mathbf{6 6} \pm \mathbf{3}$ & $\mathbf{9 3} \pm \mathbf{9}$ & $\mathbf{9 0} \pm \mathbf{5}$ \\
9 and 10 & - & - & + & $84 \pm 7$ & $56 \pm 23$ & $73 \pm 2$ & $63 \pm 22$ \\
11 and 12 & + & - & + & $79 \pm 1$ & $66 \pm 17$ & $42 \pm 18$ & $57 \pm 5$ \\
13 and 14 & - & + & + & $52 \pm 7$ & $49 \pm 14$ & $56.3 \pm 0.8$ & $57 \pm 8$ \\
15 and 16 & + & + & + & $70 \pm 3$ & $53 \pm 6$ & $72 \pm 7$ & $81 \pm 1$ \\
\hline
\end{tabular}

$\mathrm{F} 1=$ Ratio $\mathrm{v} / \mathrm{v}$ (water:acetonitrile:ethyl acetate), $\mathrm{F} 2=\mathrm{NaCl}$ concentration $\left(\mathrm{mol} \mathrm{L}^{-1}\right)$, and F3 = Stirring mode.

The replicates were used to calculate the average recovery percentages, the effects of each factor and the interactions between the factors in the extraction of each of the pesticides. The calculations were done with the Excel ${ }^{\circledR}$ and OriginPro® programs. The errors associated with each effect and their interactions were evaluated by t-test for $95 \%$ probability $(\alpha=0.05)$ and 8 replicates $(n=8)$. Some results of the statistical analysis are presented in Table 3.

Table 3. Average recovery percentages, effects of each factor and interactions between the factors ( \pm estimate of the experimental error) in the extraction of each of the pesticide, obtained in the factorial design experiments for water samples, by the SALLE method.

\begin{tabular}{lcccc}
\hline & Chlorpyrifos & Thiamethoxam & Cypermethrin & Deltamethrin \\
\hline Mean recovery & $76 \pm 1$ & $57 \pm 3$ & $69 \pm 2$ & $72 \pm 3$ \\
(1) Ratio $\left(\mathrm{H}_{2} \mathrm{O}\right.$ :solvent) & $-2 \pm 3$ & $2 \pm 6$ & $1 \pm 5$ & $6 \pm 5$ \\
(2) NaCl conc. & $\mathbf{- 7} \pm \mathbf{3}^{*}$ & $3 \pm 6$ & $11 \pm 5$ & $\mathbf{1 2} \pm \mathbf{5}^{*}$ \\
(3) Stirring mode & $\mathbf{- 1 2} \pm \mathbf{3}^{*}$ & $-2 \pm 6$ & $\mathbf{- 1 6} \pm \mathbf{5}^{*}$ & $\mathbf{- 1 5} \pm \mathbf{5}^{*}$ \\
(1) and (2) & $\mathbf{1 1} \pm \mathbf{3}^{*}$ & $-2 \pm 6$ & $\mathbf{1 5} \pm \mathbf{5}^{*}$ & $\mathbf{9} \pm \mathbf{5}^{*}$ \\
(1) and (3) & $\mathbf{7} \pm \mathbf{3}^{*}$ & $4 \pm 6$ & $-8 \pm 5$ & $3 \pm 5$ \\
(2) and (3) & $\mathbf{- 1 6} \pm \mathbf{3}^{*}$ & $-14 \pm 6$ & $-4 \pm 5$ & $-3 \pm 5$ \\
(1), (2), and (3) & $-1 \pm 3$ & $-1 \pm 6$ & $8 \pm 5$ & $6 \pm 5$ \\
\hline
\end{tabular}

*(in bold) Statistically significant effect at the $95 \%$ probability level by $\mathrm{t}$-test $\left(\mathrm{t}_{\mathrm{tab}}>\mathrm{t}_{0.05}=2.306\right)$.

The results obtained from the factorial design showed that the main effect of the ratio between the sample and the extractive mixture (F1) did not have a significant effect on the recovery percentage. The variation of the $\mathrm{NaCl}$ concentration presented a significant positive effect for the extraction of deltamethrin and negative for the chlorpyrifos. The stirring mode used to homogenize the mixture had a significant negative effect on the extraction of all pesticides, except for thiamethoxam. Thus, stirring mode by vortex (F3, level -) was the most efficient for extraction of the pesticides. 
According to the results obtained from the statistical analysis, tests 7 and 8 (Table 2) showed higher recovery percentages and lower mean dispersion for the analyzed pesticides. Therefore, the sample proportion ratios: extraction solvent $(3.0 \mathrm{~mL}$ of water, $5.0 \mathrm{~mL}$ of acetonitrile and $1.0 \mathrm{~mL}$ of ethyl acetate), $\mathrm{NaCl}$ at $2.0 \mathrm{~mol} \mathrm{~L}^{-1}$ and stirring with the vortex mixer for $40 \mathrm{~s}$ were chosen as the best conditions.

\subsection{Optimized SALLE method}

The optimized method for the extraction of pesticides consists of placing $3.00 \mathrm{~mL}$ of the water sample, $6.0 \mathrm{~mL}$ of the extraction mixture $(5.0 \mathrm{~mL}$ of acetonitrile and $1.0 \mathrm{~mL}$ of ethyl acetate) in transparent glass bottles $(22 \mathrm{~mL})$ to form a single phase. To break this equilibrium (salting-out effect) should be added $1.0 \mathrm{~mL}$ of $\mathrm{NaCl}$ solution at $2.0 \mathrm{~mol} \mathrm{~L}^{-1}$. The mixture is homogenized in the vortex mixer for $40 \mathrm{~s}$ and kept at rest (about
$1 \mathrm{~min}$ ), forming a two-phase system. The upper organic phase is withdrawn with an automatic pipette, and its volume adjusted in volumetric flask to $5.0 \mathrm{~mL}$. The extract was stored in the freezer for further analysis by gas chromatography.

\subsection{Method validation}

The SALLE method for determination of pesticides in water was validated and the results are adequate, according to the validation standards of several regulatory agencies. The values of the retention time of the compounds, calibration curve equation, and coefficient of determination, linear range, limit of detection, and limit of quantification for the developed method to analyze pesticides residues in water are represented in Table 4.

Table 4. Retention time $\left(\mathrm{R}_{\mathrm{t}}\right)$, calibration curve equation, the coefficient of determination $\left(\mathrm{R}^{2}\right)$, linear range, limit of detection (LOD), and limit of quantification (LOQ) of SALLE method.

\begin{tabular}{lllllll}
\hline Pesticide & $\mathrm{R}_{\mathrm{t}}(\min )$ & $\begin{array}{l}\text { Calibration curve } \\
\text { equation } \\
(y=\mathrm{ax}+\mathrm{b})\end{array}$ & $\mathrm{R}^{2}$ & $\begin{array}{l}\text { Linear range } \\
\left(\mu \mathrm{g} \mathrm{L}^{-1}\right)\end{array}$ & $\begin{array}{l}\mathrm{LOD} \\
\left(\mu \mathrm{g} \mathrm{L}^{-1}\right)\end{array}$ & $\begin{array}{l}\mathrm{LOQ} \\
\left(\mu \mathrm{g} \mathrm{L}^{-1}\right)\end{array}$ \\
\hline Chlorpyrifos & 5.7 & $\mathrm{y}=0.087 \mathrm{x}-0.033$ & 0.994 & $0.5-6.0$ & 0.15 & 0.5 \\
Thiamethoxam & 5.9 & $\mathrm{y}=0.005 \mathrm{x}+0.360$ & 0.990 & $18-450$ & 5.50 & 18.2 \\
Cypermethrin & 10.9 & $\mathrm{y}=0.024 \mathrm{x}+0.813$ & 0.992 & $5.0-60$ & 1.50 & 5.0 \\
Deltamethrin & 13.2 & $\mathrm{y}=0.005 \mathrm{x}+0.155$ & 0.993 & $12-150$ & 3.70 & 12.0 \\
\hline
\end{tabular}

The selectivity of the method was evaluated by applying the optimized conditions in pesticide-free water samples (white). Subsequently, these samples were fortified with the pesticides under study and again submitted to the extraction and analysis method. No interferences were observed in the retention time of the studied pesticides, proving the selectivity of the method.

The limits of detection (LOD) and quantification (LOQ) of the SALLE method for the water samples were determined considering the value of three and ten times the area of the baseline signal (noise), respectively. The LOD values for the four pesticides ranged from 0.15 to $5.5 \mu \mathrm{g} \mathrm{L}^{-1}$, whereas LOQ ranged from 0.5 to $18.2 \mu \mathrm{g} \mathrm{L}^{-1}$ (Table 4).

The LOQs found for the pyrethroids (cypermethrin and deltamethrin) are below the maximum residue limit (MRL) established by the Brazilian Ministry of Health (Portaria
$\left.\mathrm{N}^{\circ} 2914 / 2011\right)^{7}$, for permethrin, which is $20 \mu \mathrm{g} \mathrm{L}^{-1}$, a pesticide of the same class. According to the Ministry of Health, the MRL allowed for chlorpyrifos in water is $30 \mu \mathrm{g} \mathrm{L} \mathrm{L}^{-1}$, being much higher than the LOQ $\left(0.5 \mu \mathrm{g} \mathrm{L}^{-1}\right)$ found for this pesticide in this study. Although the MRL for thiamethoxam is not established in Ministry of Health, the drinking standard was established for other health-risk pesticides such as mancozeb, carbendazim, diuron, alachlor, endosulfan and trifluralin, profenofos and glyphosate, which is a value $\geq 20 \mu \mathrm{g} \mathrm{L}^{-1}$, higher than the LOQ found for this pesticide in this study.

Similar results were found by Vieira et al. (2007) when analyzing pyrethroids in water samples using liquid-liquid extraction with low temperature partitioning (LLE/LTP) and GCECD analysis. In that study, the limit of detection and quantification obtained for cypermethrin was 1.9 and $2.7 \mu \mathrm{g} \mathrm{L}^{-1}$ and for deltamethrin it was 2.9 
and $5.5 \mu \mathrm{g} \mathrm{L}^{-1}$, respectively ${ }^{26}$. In addition, the use of this same technique to extract pesticides in water has found LOD equal to $3.4 \mu \mathrm{g} \mathrm{L}^{-1}$ and LOQ equal to $10 \mu \mathrm{g} \mathrm{L}^{-1}$ for chlorpyrifos ${ }^{14}$. When analyzing the pesticides residues in pineapple samples using the SLE-LTP method, Costa Moraes et al. (2014) obtained the LOD equal to $15 \mu \mathrm{g} \mathrm{kg}^{-1}$ and LOQ equal to $50 \mu \mathrm{g} \mathrm{L}^{-1}$ for thiamethoxam, and LOD equal to $12 \mu \mathrm{g} \mathrm{kg}^{-1}$ and LOQ equal to $40 \mu \mathrm{g} \mathrm{L}^{-1}$ for deltamethrin ${ }^{10}$. However, for all the studied analytes the LOQs found for the proposed method are lower than others in the literature.

The linearity of the method was evaluated by an analytical curve equation obtained with eight points, by means of regression, including the first point of the analytical curve equals to the LOQ of the method for each tested pesticide. The extracts from samples that were fortified with the pesticides obtained using the SALLE method was injected and analyzed by GC-ECD. The analytical curves were made using the ratios between the areas of the analytes and the internal standard, thus obtaining regression equations and coefficients of determination. The coefficients of determination $\left(\mathrm{R}^{2}\right)$ for the analytical curves of the four pesticides were higher than 0.99. These results are shown in Table 4.

The precision was evaluated in terms of repeatability and intermediate precision and expressed by the coefficient of variation $(\mathrm{CV})$ associated with the relative responses of the pesticides in each test. (Table 5). The repeatability of the method was determined in samples of water fortified with the standards of cypermethrin $\left(30.0 \mu \mathrm{g} \mathrm{L}^{-1}\right)$, chlorpyrifos $(3.0 \mu \mathrm{g}$ $\left.\mathrm{L}^{-1}\right), \quad$ deltamethrin $\left(72.0 \mu \mathrm{g} \mathrm{L}^{-1}\right) \quad$ and thiamethoxam $\left(110 \mu \mathrm{g} \mathrm{L}^{-1}\right)$ at the $6 \mathrm{x}$ LOQ concentration of the method, with seven replicates and submitted to the SALLE method. Intermediate precision was evaluated by the same analyst, using the same instrument and on three distinct days (1st, 7th and 30th), with seven repetitions in the concentration referring to $6 \mathrm{x}$ LOQ of the method (Table 5). The accuracy of the method was evaluated in triplicate by recovery assays at four concentration levels $(1,3$, 6 , and $12 \times$ LOQ). Significance tests using the Student's t-test were also performed to evaluate the veracity of the method.

Table 5. Recovery and coefficient of variation of the SALLE extracted and analyzed fortified water samples.

\begin{tabular}{|c|c|c|c|c|c|c|}
\hline \multirow{3}{*}{ Pesticide } & \multicolumn{4}{|c|}{ Accuracy } & \multirow{2}{*}{\multicolumn{2}{|c|}{$\begin{array}{cc}\begin{array}{c}\text { Repeatability } \\
\text { (Intra-day) }\end{array} & \begin{array}{c}\text { Intermediate } \\
\text { precision } \\
\text { (Inter-day) }\end{array} \\
\text { Coefficient of variation }(\%)\end{array}$}} \\
\hline & \multicolumn{4}{|c|}{ Recovery (\%) } & & \\
\hline & $\begin{array}{c}\text { LOQ } \\
\left(\mu \mathrm{g} \mathrm{L}^{-1}\right)\end{array}$ & $\begin{array}{l}3 \times \text { LOQ } \\
\left(\mu \mathrm{g} \mathrm{L}^{-1}\right) \\
\end{array}$ & $\begin{array}{r}6 \times \text { LOQ } \\
\left(\mu \mathrm{g} \mathrm{L}^{-1}\right) \\
\end{array}$ & $\begin{array}{r}12 \times \mathrm{LOQ} \\
\left(\mu \mathrm{g} \mathrm{L}^{-1}\right) \\
\end{array}$ & $\begin{array}{l}6 \times \mathrm{LOQ} \\
\left(\mu \mathrm{g} \mathrm{L}^{-1}\right)\end{array}$ & $\begin{array}{l}6 \times \mathrm{LOQ} \\
\left(\mu \mathrm{g} \mathrm{L}^{-1}\right) \\
\end{array}$ \\
\hline Chlorpyrifos & 81.3 & 79.7 & 83.1 & 81.4 & 6.8 & 6.4 \\
\hline Thiamethoxam & 72.2 & 74.8 & 77.9 & 74.1 & 8.1 & 8.3 \\
\hline Cypermethrin & 87.8 & 89.6 & 87.4 & 88.8 & 5.7 & 6.7 \\
\hline Deltamethrin & 87.8 & 88.1 & 86.7 & 90.1 & 5.4 & 5.5 \\
\hline
\end{tabular}

*LOD: limit of detection; LOQ: limit of quantification

Considering the obtained results, the proposed SALLE method for the four pesticides is simple, with good extraction efficiency (72$90 \%$ and coefficients of variation for intermediate accuracy and repeatability less than $9 \%$.

The results obtained using the SALLE method for determination of chlorpyrifos, thiamethoxam, cypermethrin and deltamethrin pesticides in water were compared with those obtained by two other methods: method $1-$ liquid-liquid extraction with low temperature partitioning - LLE-LTP $^{26}$ and method 2 liquid-liquid extraction $-\mathrm{LLE}^{27}$. All water samples were fortified to obtain an extract with a final concentration equal to $6 \mathrm{x}$ LOQ of the equivalent method to each target analyte (Table 6). 
Table 6. Recovery (\%) and coefficients of variation (\%) obtained from the extraction of water samples with the pesticides chlorpyrifos $\left(3.0 \mu \mathrm{g} \mathrm{L}^{-1}\right)$, thiamethoxam $\left(110.0 \mu \mathrm{g} \mathrm{L}^{-1}\right)$, cypermethrin $\left(30.0 \mu \mathrm{g} \mathrm{L}^{-1}\right)$ and deltamethrin $\left(72.0 \mu \mathrm{g} \mathrm{L}^{-1}\right)$ in triplicates using the SALLE method and two methods used as reference.

\begin{tabular}{lllll}
\hline & \multicolumn{4}{c}{ Recovery $(\%)$ and CV $(\%)$} \\
\cline { 2 - 5 } & Chlorpyrifos & Thiamethoxam & Cypermethrin & Deltamethrin \\
\hline Method 1 & $80 ; 5$ & $76 ; 9$ & $87 ; 6$ & $83 ; 5$ \\
Method 2 & $83 ; 9$ & $79 ; 6$ & $75 ; 5$ & $83 ; 6$ \\
SALLE & $86 ; 6$ & $77 ; 8$ & $91 ; 6$ & $89 ; 6$ \\
\hline
\end{tabular}

Method 1 - liquid-liquid extraction with low temperature partitioning - LLE-LTP ${ }^{26}$ and method 2- liquid-liquid extraction - $\mathrm{LLE}^{27}$.

Considering the proximity between the results obtained by the SALLE method and methods 1 and 2, it can be concluded that both methodologies did not show large dispersion of the coefficients of variation. The recovery percentages obtained for chlorpyriphos, thiamethoxam and deltamethrin did not differ statically (95\% probability) in the three methods studied, with the exception of cypermethrin, which presented higher extraction efficiency in the SALLE method $(91 \%)$ than method $2(75 \%)$. When comparing method 1 with SALLE, both are efficient, using small volumes of sample and solvents. The SALLE method requires less time for phase separation (one minute) while method 2 requires $12 \mathrm{~h}$ for forming a two-phase system. The method 2 has the advantage of preconcentrating the analyte from water samples, approximately equal to 3 times. However, it is important to note that during this process, matrix impurities are concentrated together with the analyte. In addition, a relatively large volume of samples $(25.0 \mathrm{~mL})$ and solvents $(135.0 \mathrm{~mL})$ are required in method 2, generating greater problems of environmental contamination and risks to the health of the analyst. On the other hand, the SALLE method requires a small amount of sample $(3.0 \mathrm{~mL})$ and solvent $(6.0 \mathrm{~mL})$ for the determinations (Table 6).

The optimized and validated SALLE method was applied to samples of water collected in rivers of the Zona da Mata of the State of Minas Gerais (Brazil) and in points of the water treatment station of the Universidade Federal de Viçosa (Viçosa, Minas Gerais, Brazil). However, none of the four pesticides investigated were detected in any of the analyzed samples or were in concentrations below the limit of detection of the method. Considering that the half-life, mainly of the pyrethroids, is relatively short ${ }^{26}$, a way to increase the probability of detecting contamination in the water resources would be collecting the samples in the period in which the application of the pesticides coincided with the rainy season, when it is expected an increase in the pesticide application.

After obtaining the results of the analysis of the water collected in the rivers of the Zona da Mata and verified the exemption of the pesticides under study, three samples of water from rivers that presented a more turbid aspect due to the particulate material were contaminated with known amounts of the four pesticides. Subsequently, without any previous treatment, these fortified natural samples were submitted to the optimized and validated extraction method in order to evaluate the matrix effect and its selectivity. Comparatively, the recovery rates and the coefficients of variation of the analyzes are statistically similar, with no matrix effect in the results (Table 7).

Table 7. Recovery (\%) and coefficients of variation (\%) obtained from the extraction of distilled and fortified natural water samples with the pesticides chlorpyrifos $\left(3.0 \mu \mathrm{g} \mathrm{L}^{-1}\right)$, thiamethoxam $\left(110.0 \mu \mathrm{g} \mathrm{L} \mathrm{L}^{-1}\right)$, cypermethrin $\left(30.0 \mu \mathrm{g} \mathrm{L}^{-1}\right)$ and deltamethrin $\left(72.0 \mu \mathrm{g} \mathrm{L}^{-1}\right)$ using the SALLE method.

\begin{tabular}{lllll}
\hline & \multicolumn{4}{c}{ Recovery $(\%)$ and CV $(\%)$} \\
\cline { 2 - 5 } & Chlorpyrifos & Thiamethoxam & Cypermethrin & Deltamethrin \\
\hline Distilled water & $83 ; 7$ & $76 ; 7$ & $90 ; 7$ & $85 ; 6$ \\
Sample 1 & $81 ; 6$ & $77 ; 9$ & $91 ; 8$ & $90 ; 6$ \\
Sample 2 & $82 ; 6$ & $80 ; 9$ & $90 ; 7$ & $88 ; 5$
\end{tabular}




\section{Conclusions}

The optimized and validated salting-out assisted liquid-liquid extraction (SALLE) method for analyzing by gas chromatography (GC/ECD) is simple, inexpensive, fast, efficient, with high recovery percentages and good repeatability, allowing its use to detect pesticides in environmental samples.

The recovery percentages were higher than $72 \%$ and the coefficient of variation was lower than $9 \%$. The main advantage of the SALLE method followed by GC/ECD analysis was the low consumption of sample $(3.0 \mathrm{~mL})$ and solvent $(6 \mathrm{~mL})$, and shorter time for phase separation $(1 \mathrm{~min})$, allowing its use in routine analysis of the pesticides in water samples. Hence, it seems possible to extend this method to extract the compounds of interest in other similar samples by varying the extraction conditions.

\section{Acknowledgements}

We would like to thank the following Brazilian agencies for their financial support: Fundação de Amparo à Pesquisa do Estado de Minas Gerais (FAPEMIG), Conselho Nacional de Desenvolvimento Científico e Tecnológico $(\mathrm{CNPq})$ and Coordenação de Aperfeiçoamento de Pessoal de Nível Superior (CAPES).

\section{References}

[1] Carlos, E. A., Alves, R. D., Queiroz, M. E. L. R., Neves, A. A., Simultaneous determination of the organochlorine and pyrethroid pesticides in drinking water by single drop microextraction and gas chromatography, J. Braz. Chem. Soc. 24 (2013) 1217-1227. https://doi.org/10.5935/01035053.20130155 .

[2] Cassal, V. B., Azevedo, L. F., Ferreira, R. P., Silva, D. G., Simão, R. S., Agrotóxicos: uma revisão de suas consequências para a saúde pública, Revista Eletrônica em Gestão, Educação e Tecnologia Ambiental - (REGET) 18 (1) (2014) 437-445. https://doi.org/10.5902/2236117012498.

[3] Soares, D. F., Faria, A. M, Rosa, A. H., Análise de risco de contaminação de águas subterrâneas por resíduos de agrotóxicos no município de Campo Novo do Parecis (MT), Brasil, Eng. Sanit. Ambient. $22 \quad$ (2) (2017) 277-284. https://doi.org/10.1590/S1413-41522016139118.

[4] IBGE - Instituto Brasileiro de Geografia e Estatística, Atlas de Saneamento 2011. Available from:

http://www.ibge.gov.br/home/estatistica/populaca o/atlas_saneamento/default_zip.shtm (accessed Apr 2017).

[5] Van Der Werf, H. M. G., Assessing the impact of pesticides on the environment, Agric. Ecosyst. Environm. 60 (1996) 81-96. https://doi.org/10.1016/s0167-8809(96)01096-1.

[6] Holvoet, K. M. A., Seuntjens, P, Vanrolleghem, P. A., Monitoring and modeling pesticide fate in surface waters at the catchment scale, Ecol. Model. 209 (2007) 53-64. https://doi.org/10.1016/j.ecolmodel.2007.07.030

[7] BRASIL. Portaria $\mathrm{n}^{\mathrm{o}} 2.914$ de 12 de dezembro de 2011. Dispõe sobre os procedimentos de controle e de vigilância da qualidade da água para consumo humano e seu padrão de potabilidade. Diário Oficial da União. 12 dez. 2011.

[8] Brondi, S. H. G., Lanças, F. M., Development and Validation of a Multi-Residue Analytical Methodology to Determine the Presence of Selected Pesticides in Water Through Liquid Chromatography, J. Braz. Chem. Soc. 16 (2005) 650-653.

https://doi.org/101590/s0103.505320050004000 26.

[9] Tankiewicz, M., Fenik, J., Biziuk, M., Solventless and solvent-minimized sample preparation techniques for determining currently used pesticides in water samples: a review, $\begin{array}{llll}\text { Talanta } & 86 & \text { (2011) } & \text { 8-22. }\end{array}$ https://doi.org/10.1016/j.talanta.2011.08.056.

[10] Costa Morais, E. H., Rodrigues, A. A. Z., Queiroz, M. E. L. R., Neves, A. A., Morais, P. H. D., Determination of thiamethoxam, triadimenol and deltamethrin in pineapple using SLE-LTP extraction and gas chromatography, Food Control 
42

(2014)

9-17.

https://doi.org/10.1016/j.foodcont.2014.01.024.

[11] Rodrigues, A. M., Ferreira, V., Cardoso, V. V., Ferreira, E., Benoliel, M. J., Determination of several pesticides in water by solid-phase extraction, liquid chromatography and electrospray tandem mass spectrometry, J. Chromatog. A 1150 (2007) 267-278 https://doi.org/10.1016/j.chroma.2006.09.083.

[12] Farajzadeh, M. A., Matin, A. A. Determination of BTEX in water samples with an SPME hollow fiber coated copper wire,

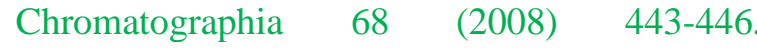
https://doi.org/10.1365/s10337-008-0726-z.

[13] Goulart, S. M., Alves, R. D., Neves, A. A., Queiroz, J. H., Assis, T. C., Queiroz, M. E. L. R. Optimization and validation of liquid-liquid extraction with low temperature partitioning for determination of carbamates in water, Anal. Chim. $\begin{array}{llll}\text { Acta } & 671 & (2010) & 41-47 .\end{array}$ https://doi.org/10.1016/j.aca.2010.05.003.

[14] Silvério, F. O., Silva, J. G. S., Aguiar, M. C. S., Cacique, A. P., Pinho, G. P., Análise de agrotóxicos em água usando extração líquidolíquido com partição em baixa temperatura por cromatografia líquida de alta eficiência, Quím. $\begin{array}{llll}\text { Nova } & 35 & \text { (2012) 2052-2056. }\end{array}$ https://doi.org/10.1590/S010040422012001000027.

[15] Huang, S. P., Huang, S. D., Determination of organochlorine pesticides in water using solvent cooling assisted dynamic hollow-fibersupported headspace liquid-phase microextraction, J. Chromatogr. A 1176 (2007) 19-25.

https://doi.org/10.1016/j.chroma.2007.10.073.

[16] Young, A., Lai, G., Hung, B., Yuen, A., He, Y., Determination of trace chloroanilines in environmental water samples using hollow fiberbased liquid phase microextraction,

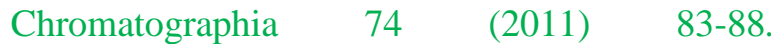
https://doi.org/10.1007/s10337-011-2022-6.

[17] Rezaee, M., Assadi, Y., Hosseini, M. R. M., Aghaee, E., Ahmadi, F., Berijani, S., Determination of organic compounds in water using dispersive liquid-liquid microextraction, J. $\begin{array}{lllll}\text { Chromatogr. A } & 1116 \quad \text { (2006) } & \text { 1-9. }\end{array}$ https://doi.org/10.1016/j.chroma.2006.03.007.

[18] Chen, H., Chen, R., Li, S., Low-density extraction solvent-based solvent terminated dispersive liquid-liquid microextraction combined with gas chromatography-tandem mass spectrometry for the determination of carbamate pesticides in water samples, J. Chromatogr. A 1217 (2010) 1244-1248. https://doi.org/10.1016/j.chroma.2009.12.062.

[19] Soares, C. E., Neves, A. A., Queiroz, M. E. L. R., Oliveira, A. F., Costa, A. I. G., Assis, R. C., Andrade, C. E., Single drop microextraction: a sensitive multiresidue method for determination of pesticides in water using GC/ECD, J. Braz. Chem. Soc. 25 (2014) 2016$2025 . \quad$ https://doi.org/10.5935/01035053.20140186.

[20] Anastassiades, M., Lehotay, S. J., Stajnbaher, D. Schenck, F. J. Fast and easy multiresidue method employing acetonitrile extraction/partitioning and "dispersive solidphase extraction" for determination of pesticides residues in produce, Journal of AOAC Int. 8 (2003) 412-431.

[21] Pawliszyn, J. Solid phase microextraction: theory and practice, Wiley-VCH, New York, 1997.

[22] Collins, C. H., Braga, G. L., Bonato, P. S. Fundamentos de Cromatografia, editora Unicamp. Campinas, 2006.

[23] ICH, Validation of analytical procedures: text and methodology Q2 (R1). In Proceedings of the International Conference on Harmonisation of Technical Requirements for Registration of Pharmaceuticals for Human Use; 2005 25-27.

[24] ANVISA, Guia para validação de métodos analíticos e bioanalíticos. In Resolução RE $n^{\circ} 899$, de 29 de maio de 2003; 2003.

[25] INMETRO, Instituto Nacional de Metrologia, Normalização e Qualidade Industrial. DOQ-CGCRE 008: Orientações obre validação de métodos de ensaios químicos. INMETRO: Rio de Janeiro, 2010. 
[26] Vieira, H. P., Neves, A. A., Queiroz, M. E. L. R., Otimização e validação da técnica de extração líquido-líquido com partição em baixa Temperatura (ELL-PBT) para piretróides em água e análise por CG, Quím. Nova 30 (2007) 535-540. https://doi.org/10.1590/S010040422007000300006.

[27] Vinas, P., Campillo, N., Garcia, L., Aguinaga, N., Cordoba, M. H. Determination of pesticides in waters by capillary gas chromatography with atomic emission detection, J. Chromatogr. A 978 (2002) 249-256. https://doi.org/10.1016/s0021.9673(02)01443-7. 